
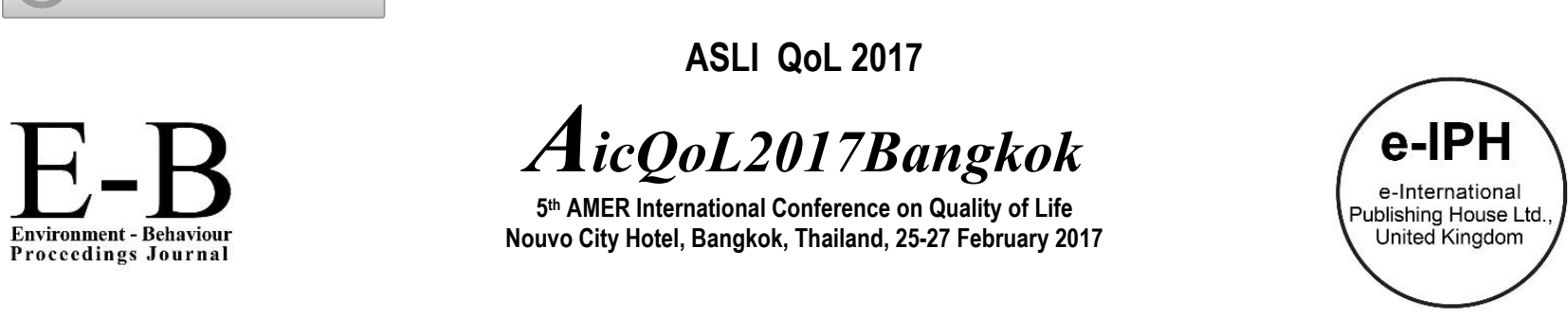

\title{
Exploring the Elements of Natural Landscape Character in Engaging Children with their Natural Environment
}

\author{
Marina Abdullah ${ }^{1 *}$, Wan Noor Anira Wan Ali1 ${ }^{1}$ Izham Ghani ${ }^{1}$ \\ ${ }^{1}$ Faculty of Architecture, Planning \& Surveying, Universiti Teknologi MARA, 32610 Seri Iskandar, Perak
}

\begin{abstract}
Exploration process will increase the experience of children's life primarily during their learning stages. The process of exploration helps children to get closer to nature and appreciate its surroundings. The elements of natural landscape character may potentially enable children to be more creative in gaining experience and increase new knowledge. Children learn best through free play and discovery (White, 1998). It will stimulate their positive senses, emotions and social interaction among other children and its environment. This research focuses on the investigation of the favourite place for children ages 5 and 6 years old. This research will strengthen the engagement of children experience with nature. However, there are constraints which are limiting the natural environment exposure with the children. Therefore, the elements of the natural landscape should be integrated with consideration to the children's needs and the natural environment.
\end{abstract}

Keywords: Natural landscape, children exploration, natural environment

ISSN: 2398-4287@ 2017. The Authors. Published for AMER ABRA by e-International Publishing House, Ltd., UK. This is an open access article under the CC BYNC-ND license (http://creativecommons.org/licenses/by-nc-nd/4.0/). Peer-review under responsibility of AMER (Association of Malaysian Environment-Behaviour Researchers), ABRA (Association of Behavioural Researchers on Asians) and cE-Bs (Centre for Environment-Behaviour Studies), Faculty of Architecture, Planning \& Surveying, Universiti Teknologi MARA, Malaysia.

\begin{abstract}
1.0 Introduction
The influence of family and environmental factors are significant towards children's' development. This study was conducted to determine the selection of the children's preferred place as they want in the process of getting closer to the natural environment. With this, pre-school or kindergarten is transmitting experience and learning of children. Kindergartens should be required to provide an appropriate space for learning and exploration for children. The case study focuses on photos taken around the sights in Taiping, Perak. All of these places will be arranged according to the level of naturalness and spectrum modification based on the theory by Miskell (2011). Each selected area contains natural landscape elements such as plants, water, land and others. Taman Tasik Taiping, Burmese Pool (Bukit Larut), Kuala Sepetang and Water Theme Park in Bukit Merah are selected to be evaluated by the selected children. The children need to choose a rating option for their favourite place to go. In this study, elements that are important to them and the wishes of the child's developmental exploration are considered significant to add to their experience with the environment. In addition, it may be able to make children love their natural environment. Children around Seri Iskandar's kindergartens aged between 5 and 6 years old are selected as participants in this study. The sampling selection for the age group of 5 and 6 years old children are recommended by the kindergarten teacher to see the comparison and reaction of children to environmental conditions while helping them to provide better space for the exploration and expression. Moreover, at this age children can talk, write, and conduct other activities independently and able to observe each element in the environment such as water, stone, fruit, trees, soil and others, as compared to those at infancy age.
\end{abstract}

\subsection{The development of children age 5 and 6 years old}

Children are the stakeholder in this study because they are the driving force for the foreseeable future. They need to be educated to appreciate the nature and natural landscape so that it will always be protected and preserved. According to the theory by Havighurst

\footnotetext{
* Corresponding author. Tel.: 019-7086307 / 05-3742591

E-mail address: marina84@perak.uitm.edu.my
}

ISSN: 2398-4287@ 2017. The Authors. Published for AMER ABRA by e-International Publishing House, Ltd., UK. This is an open access article under the CC BYNC-ND license (http://creativecommons.org/licenses/by-nc-nd/4.0/). Peer-review under responsibility of AMER (Association of Malaysian Environment-Behaviour Researchers), ABRA (Association of Behavioural Researchers on Asians) and cE-Bs (Centre for Environment-Behaviour Studies), Faculty of Architecture, Planning \& Surveying, Universiti Teknologi MARA, Malaysia.

DOI: http://dx.doi.org/10.21834/e-bpj.v2i5.695 
(1953), stages of child development is divided into three stages. The first stage is the stage of infancy (0-2years) and early childhood (3-6 years) where they begin to talk, interacts with others and learns to distinguish between right and wrong. The second level is the middle level (7-12 years old) where they begin to make friends with others; understand the concept of life and morals. The third stage of the initial stage of early adolescence (13-15 years old), and late adolescence or youth (16-19 years) where they are almost matured and can recognise the concept of good and bad in life, as well as able to control the psychomotor, cognitive and emotional development. According to Islamic scholars, this division is generated based on the observation of the development of the physical, mental and emotional.

This study is focused on children in the first stage, aged 5 to 6 years old. At this stage, they start to develop self-concept, identity, gender role and love to play with their surroundings. Besides, the child is starting to show psychomotor skills and starts developing cognitive and emotions. Parents and people close to them have to be more critical in creating bonding. Through interviews with many of the kindergarten teachers, they also suggest studies that are appropriate for this age level. Based on the observations made in several interviews with kindergarten and kindergarten teachers shows that most children at this age of 5 years old was very active and did not fully understand the concept of ethics. Meanwhile, they are very respectful, brave to face for highlighting the advantages of each of them and do not be embarrassed to talk about anything. They are very loud talking and closely interact with friends around them. Ames et al. (2012) mentioned in her book, the character of children at the age of 5 years old is more on the positive side. They try to be successful in any activities that they are involved. Moreover, they are very concern about their living environment. This selflimiting and protective category of a child is less attracted in seeking new activities but prefer to positively be able to measure their ability that they can confidently conduct and avoid things that they're not capable.

Furthermore, Ames et al. (2012) stated that children at the age of 6 years old are more enthusiastic. They could be considered as growing more matured, love adventures, attracted to new games, trying to be more independent, more daring, yet very sensitive and emotional. They are not willing to listen to any comments or criticism on them, especially when they considered themselves being excellent. Meanwhile, from the observations at kindergarten, most of these aged 6 children are very cautious when speaking. Most of them will listen to instructions before making any action, in contrast to children aged 5 years.

\subsection{The relationship between natural landscape character and children}

A natural landscape character is a piece of land, and the elements are not directly moved, altered or changed by peoples. Natural landscape character remains intact if the living and non-living elements of that natural environment are free to move and change. It is also related to the elements of landscape either living or non-living, including rock, water, and vegetation. A natural landscape character is used to describe the natural attributes into three primary components such geology, landform and vegetation (Smale, 1994). Based on the attributes, he believed that unmodified, original, indigenous landscapes areas clearly had a very high degree of natural character. Studies conducted by Boffa Miskell and Lucas Associates (2011), and Froude (2011) revealed that the greatest naturalness is where the modification is least and the nature character is still origin.

The quality of naturalness can create many different feelings, emotion and more positive (Spitalas N., 2000). He noted that in a design environment, the elements of the natural landscape are significant such as water, plants, stones and soils. For example, water elements which consist of sounds, reflection and movement are vital as part of the design elements. Spitalas N. (2000) and Eleftheriadis (2006), stated that water is a powerful element of the natural landscape. The values of water elements are derived from the existence of water and categorised into: (i) the movements of rivers, waterfalls, wave, and others; (ii) the colour of water; (iii) the reflections on the water surface and (iv) the opportunities for environmental education. The water elements provide a sense of stimulation where children sense it through image and sounds (Eleftheriadis, 2006). The water can cause memorial and emotional impacts with its tranquil and sensitive properties (Spitalas, 2000; Eleftheriadis, 2006).

In 'Environmental Performance Indicators for Natural Character' workshop held in 2002 mentioned that natural landscape character could give a positive impact on human perception and emotion, especially to kids or children. Korpela et al. (2002) studied that children used their favourite places for cognitive restoration and one-third for emotional regulation. Some study shows that children who are in contact with nature scored higher on the test of self-discipline (Wells 2000, Taylor et al. 2002). The exposure to natural landscape or environment can develop children's cognitive and collaborative skills (Moore \& Wong, 1997; Taylor et al., 1998; Fjortoft, 2000), as well as improve their awareness, reasoning and observational skills (Pyle 2002). Furthermore, according to Kellert (2002), children need various (direct, indirect, and vicarious) contacts with nature to develop their personality harmoniously. Bixler et al. (2002) revealed that natural landscape helps to stimulate children in their social interaction between communities. The environment helps them to be independent and autonomy. According to Crain (2001), natural environments or natural landscape helps children develop powers of observation and also instils a sense of peace. Pre-school children are usually interested in the natural environment and explore natural elements during most of their time outdoors (Heerwagen and Orians, 2002). Throughout most of history, when children were free to play, their first choice was often to flee to the nearest wild place, whether it was a big tree or brushy area in the yard or a watercourse or woodland nearby (Pyle 2002).

Also, the natural landscape gives many opportunities for children to develop an environmental ethic through regular contact with nature. It is also contributed significantly to children's and community well-being and quality of life. According to White Hutchinson Leisure and Learning Group (2011), elements of natural environments that children like includes (i) water; (ii) vegetation; including trees, bushes, and flowers; (iii) places and features to sit in, on, under, lean against and provide shade; (iv) different levels and nooks and crannies, places that offer privacy and views. Besides, they also state that plants in a pleasant environment with a mix of sun, shade, colour, texture, fragrance and softness of enclosure also encourage a sense of peacefulness. 


\subsection{Methodology}

This study was conducted in three (3) phases. The details of the phases are discussed below:

Phase 1 involves the study of literature and picture taking activities around the study area.

The images are based on the attraction places in Taiping. Each image obtained will be put at the level of naturalness from modified to pristine. Regarding Miskell (2011), the 7-point scale was used, ranging from spectrum colour of red, very low (VL) totally modified to the colour green, very high $(\mathrm{V}-\mathrm{H})$ which is indigenous or pristine. This scaling attempts to include as best as possible a rating that suits different types of environments.

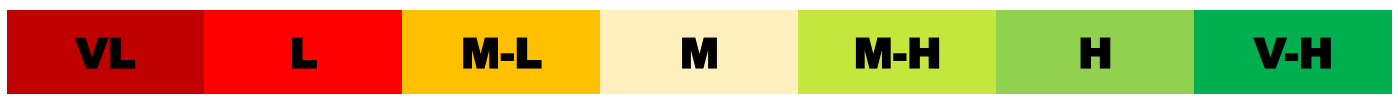

Fig. 1: Scale-like spectrum of naturalness (Source: Miskell, 2011)

However, only four images were selected and evaluated by the natural level of the child's age and their ability. Location of image VL/1 was at Bukit Merah Waterpark where it consist of water, plants and playground; image L/2 was at Kuala Sepetang, which consist of water, plants, decking and gazebo; image $\mathrm{MH} / 3$ at Taman Tasik Taiping, consist of tree, water and roadways, and lastly image label $\mathrm{H} / 4$ is at Burmese Pool, Bukit Larut. This image shows a natural waterfall consist of rock, water, and plants.

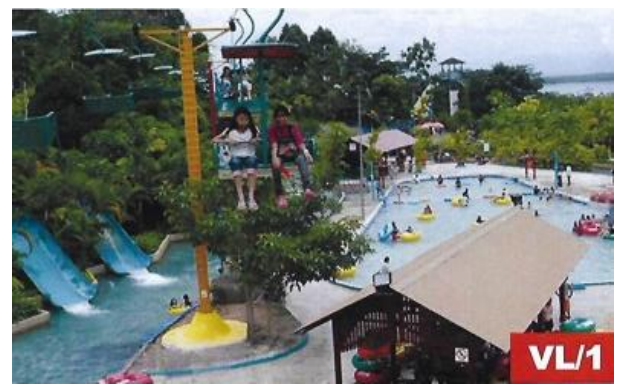

(a)

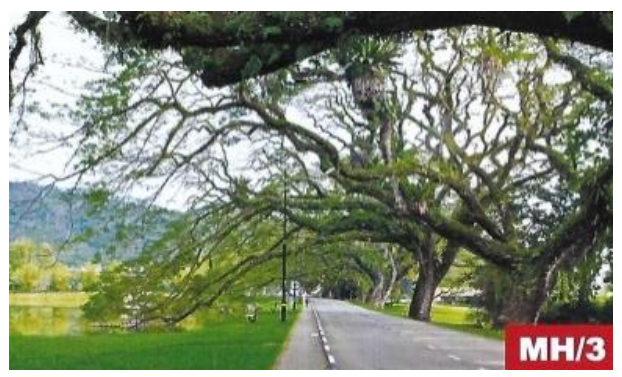

(c)

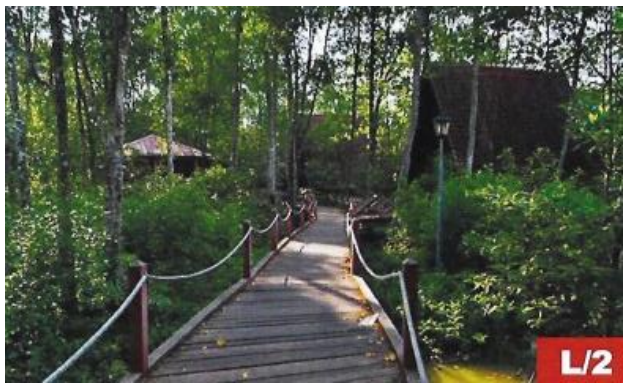

(b)

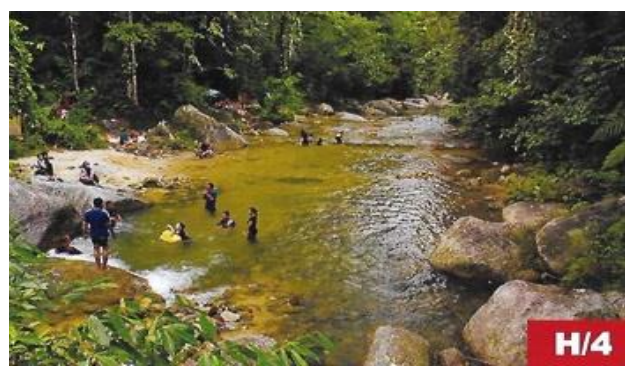

(d)

Fig. 2: (a) Bukit Merah Waterpark; (b) Kuala Sepetang; (c) Taman Tasik Taiping; (d) Burmese Pool (Source: Author, 2016)

Phase 2 involves ground study between researcher, kindergarten teachers and children aged 5 and 6 years old. This study is to carry out an experiment with children aged 5 to 6 years old, to see the order of places where they most prefer to go either in person or groups. The study phase involved three kindergartens in Seri Iskandar with the total of 19 children aged 5 years old and 20 children aged 6 years old. These are the children who attended kindergarten directly. Children will be tested on their ability to identify the elements of the natural environment around them like water, plants, soil, rain and nature. Experience sharing sessions will run alongside the children and their teachers about the importance of nature to human beings. It is for additional input, especially from the perspective of the needs of children with their environment. Activities will be conducted by the image organised by children. Each natural element in the image will be asked and explained to the children according to their age. Children will observe each image individually and produce images of the places they most prefer to go and activities that occur on places they are less likely want to go. The composition of the chosen picture vertically will be attached as proof. They were also asked to write their name on the back of the images where they most wanted to go. All the images will be recorded for analysis.

Phase 3 involves the results of data that has been recorded in the kindergartens. Each set of image analysis process will be carried out according to gender and age. This analysis process is conducted by using IBM SPSS statistic 24 software. 


\subsection{Analysis}

This is the analysis on a selection of four (4) preferred places to go for children aged 5 years old. Figure 3 shows the first place highest chosen image is VL/1 amounting to $72 \%$. Secondly is L/2 and followed by MH/3 which amounts to $43 \%$ and lastly $\mathrm{H} / 4$ amounting to $32 \%$.

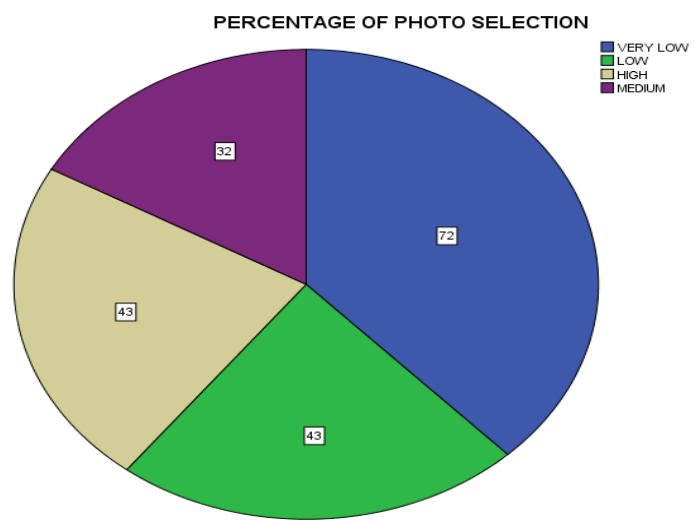

Fig. 3: Percentage of photo selection acquired by 5 years old children (Source: Author, 2016)

Table 1 shows the total number of respondents aged 5 years old at Kindergarten around Seri Iskandar according to gender.

\begin{tabular}{ccccc}
\multicolumn{5}{c}{ Table 1. Respondents of the study according to gender by 5 years old } \\
\hline Gender & Frequency & Percentage & Valid percentage & Cumulative percentage \\
\hline Boys & 8 & 42.1 & 42.1 & 42.1 \\
Girls & 11 & 57.9 & 57.9 & 100.0 \\
TOTAL & 19 & 100.0 & 100.0 &
\end{tabular}

(Source: Author, 2016)

Figure 4 shows the analysis on the selection of four (4) preferred places to go for children aged 6 years old. The first place highest chosen picture is $\mathrm{VL} / 1$ amount $71 \%$. Secondly is $\mathrm{L} / 2$ and followed by $\mathrm{MH} / 3$ amount $44 \%$ and lastly $\mathrm{H} / 4$ amounting to $41 \%$.

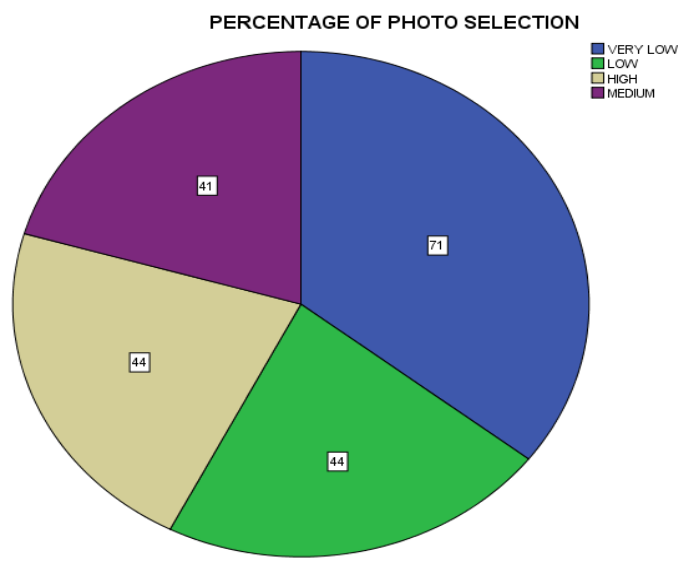

Fig. 4: Percentage of photo selection acquired by 6 years old children (Source: Author, 2016)

Table 2 shows the total number of respondents aged 6 years old at Kindergarten around Seri Iskandar according to gender.

Table 2.Respondents of the study according to gender by 6 years old

\begin{tabular}{ccccc}
\hline Gender & Frequency & Percentage & Valid percentage & Cumulative percentage \\
\hline Boys & 10 & 50.0 & 50.0 & 50.0 \\
Girls & 10 & 50.0 & 50.0 & 100.0 \\
TOTAL & 20 & 100.0 & 100.0 & \\
& \multicolumn{4}{c}{ (Source: Author, 2016) } \\
\hline
\end{tabular}




\subsection{Findings}

Table 3 shows the total number of respondents aged 5 and 6 years old at Kindergarten around Seri Iskandar

Table 3.Respondents of the study

\begin{tabular}{cccccc}
\hline & Age & Frequency & Percentage & Valid percentage & Cumulative percentage \\
\hline Valid & 5 years old & 19 & 48.7 & 48.7 & 48.7 \\
& 6 years old & 20 & 51.3 & 51.3 & 100.0 \\
& TOTAL & 39 & 100.0 & 100.0 & \\
\hline & & & (Source: Author, 2016)
\end{tabular}

Table 4 shows the Place of preferred photo selection according to aged 5 and 6 years old.

Table 4. Place of preferred photo selection according to age 5 and 6 years old

\begin{tabular}{ccccc}
\hline $\begin{array}{c}\text { Preferred } \\
\text { Selection }\end{array}$ & $\begin{array}{c}\text { Very Low } \\
(\mathrm{VL} / 1)\end{array}$ & Low $(\mathrm{L} / 2)$ & $\begin{array}{c}\text { Medium High } \\
(\mathrm{MH} / 3)\end{array}$ & High $(\mathrm{H} / 4)$ \\
\hline 1 & 87.2 & 2.6 & 0 & 10.3 \\
2 & 2.6 & 48.7 & 17.9 & 30.8 \\
3 & 5.1 & 25.6 & 56.4 & 12.8 \\
4 & 5.1 & 23.1 & 25.6 & 46.2 \\
\hline Total & 100.0 & 100.0 & 100.0 & 100.0 \\
\hline \multicolumn{5}{c}{ (Source: Author, 2016) }
\end{tabular}

Most of the respondents choose the VL/1 photo, which amounts to $87.2 \%$, but none selected the MH/3 photo. The result revealed that the entire respondent mainly prefers to choose or select very low $(\mathrm{VL})$ pictures, percentage 87.2. Then followed by high $(\mathrm{H} / 4)$ and medium high $(\mathrm{MH} / 3)$ in same percentage amount 10.3 percent. Lastly, a low (L/2) amount is 2.6 percent. The result revealed that the entire respondent prefers to choose or select very low $(\mathrm{VL})$ pictures with the water element. From the interview, view from the respondents afraid with wildlife creatures in natural setting, and discomfort with the natural facilities. They mentioned that parents do not allow communicating with nature and less being in the outdoor. A 'culture of fear' has parents afraid for their children's safety. A 2004 study found that $82 \%$ of mothers with children between the ages of 3 and 12 identified crime and safety concerns as one of the primary reasons they don't allow their children to play outdoors (Clements 2004). Moreover, parents are busy working, and less spends time leisure in the outdoor. Most of the class and activities were held in the indoor rather outdoor.

Children could explore the elements of natural landscape freely or with a guardian. However, there are factors that contribute to a failure of children's exploration of the natural environment. From the interviews with children, they mention about restriction by parents somehow leads to this issue. Nowadays parents are afraid of giving chances to children to play outside the house. Due to this, children can no longer roam around the house compound to explore the environment without adult's supervision. Discussion with the children tells that parents would more prefer their children to play inside the house especially with gadgets, watching television or computers. This has led to children with no spontaneous contact with their outdoor surrounding and which may affect their childhood experience. Pyle (1993) calls this the 'extinction of experience,' which breeds apathy towards environmental concerns. Kellert (2009) stated that direct contact with nature during childhood period had been increasingly replaced by more indirect and symbolic ways of becoming familiar with nature, such as television programs or visiting theme parks. This may lead to negative perceptions of children and disconnects "pure" feelings when standing in a natural environment. They feel insecure about safety matters which may be a direct influence from adults or guardian, wildlife and creatures when having natural exploration.

Early experience with natural landscape is important to motivate children with exciting experience when responding to their environments. Furthermore, children are free to do "messy" activities outdoors rather than indoors. Teachers in pre- school should also expose children to be closer to nature and integrate more activities in natural settings. Besides, activities that integrate children's contact with nature may reduce anxiety towards natural environments. Lynch (1977) noted that wild areas such as riverbanks, woods, and hills evoked both attraction and fear, but it gave children the freedom to be alone or with friends and act independently. Activities such as gardening, visiting zoos, water exploration, building a sand castle and much more may create an effective bonding among children and natural elements in their natural surroundings. Hart (1979) interviewed children discussing the list of natural elements that include lakes, river, trees, fields, slope for sliding, hills and the play that they created. Interestingly the study revealed that the place that captured the children's interest were a brook, a frog pond, a climbing tree, a hiding place under bushes, and a sand bank.

\subsection{Conclusion}

Overall, this study showed that the majority of children at Seri Iskandar's kindergarten are slightly less interested in nature, but there are some who preferred natural elements. Those who fall under this group category are children who had an experience in overseas pre-school. However, they have chosen the element of water as the most desired element of natural landscape for the process of exploring their natural environment. We suggest that parents should spend more time outdoors with their children for this purpose. In general, teachers also play an important role to educate and nurture children to appreciate nature by guiding them individually or en masse, via outdoor play activities that involve natural elements such as water, soil and vegetation. This will create better engagement 
and closeness to their natural environments while enhancing creativity during their learning experience. In future, research continues in exploring the character or outdoor preferred space in the school in expanding kids experience towards nature.

\section{Acknowledgements}

The work in this research is funded by Ministry of Higher Education (Malaysia) under Research Acculturation Grant Scheme (600RMI/RAGS 5/3 (132/2014)). The authors would like to acknowledge Institute of Research Management and Innovation (IRMI), Universiti Teknologi MARA for providing necessary assistance for the preparation of this research.

\section{References}

Bates Ames L. B. \& Frances L. (2012). Your Six-Year-Old: Loving and Defiant. Dell Publishing Group Inc. New York.

Boffa Miskell and Lucas Associates (2011). Canterbury Regional Landscape Study, Volume 2. Prepared for Canterbury Regional Council.

Bixler, Robert D., Floyd, Myron E. \& Hammitt, William E. (2002). Environmental Socialization: Quantitative Tests of the Childhood Play Hypothesis. Environment and Behavior, 34(6), 795-818.

Clements, R. (2004). An investigation of the status of outdoor play. Contemporary Issues in Early Childhood, 5(1) 68-80.

Crain, W. (2001). Now Nature Helps Children Develop. Montessori Life, Summer 2001.

Eleftheriadis, N. (2006). Landscape Aesthetics (orig. Greek). Landscape Architecture Dept. Drama.

Fjortoft, I. \& Sageie, J. (2000). The Natural Environment as a Playground for Children: Landscape Description and Analysis of a Natural Landscape. Landscape and Urban Planning, 48(1/2), 83-97.

Froude, V.A. (2011). Quantitative methodology for measuring the natural character of New Zealand's coastal environments. (Doctoral thesis), University of Waikato.

Hart, R. (1979). Children's Experience of Place. New York: Irvington.

Korpela, K., Kytta M. \& Hartig, T. (2002). Restorative experience, self-regulation, and children's place preferences. Journal of Environmental Psychology, 22(4), 387398.

Kellert, S.R. (2002). Experiencing nature: Affective, cognitive, and evaluative development, in children and nature: Psychological, sociocultural, and evolutionary investigations. Cambridge, MA: The MIT Press.

Moore, R. \& Wong, H. (1997). Natural Learning: Rediscovering Nature's Way of Teaching. Berkeley, CA MIG Communications.

Pyle, R. (1993). The thunder trees: Lessons from an urban wildland. Boston: Houghton Mifflin.

Pyle, R. (2002). Eden in a vacant lot: Special places, species and kids in community of life. In Kahn, P.H. and Kellert, S.R. (Eds.), Children and Nature: Psychological, Sociocultural and Evolutionary Investigations. Cambridge: MIT Press.

Smale, S. (1994). Natural character: An analysis, unpublished discussion paper, Department of Conservation, Rotorua.

Spitalas, N. (2000). Environmental Aesthetics - Architecture (orig. Greek). Christodoulidi. Thessaloniki.

Taylor, A.F., Kuo, F.E. \& Sullivan, W.C. (2002). Views of Nature and Self-Discipline: Evidence from Inner City Children. Journal of Environmental Psychology, 22, 4963.

Taylor, A.F., Wiley, A., Kuo, F.E., \& Sullivan, W.C. (1998). Growing up in the inner city: Green spaces as places to grow. Environment and Behavior, 30(1), 3-27.

Wells, N. M. (2000). At Home with Nature, Effects of "Greenness" on Children's Cognitive Functioning. Environment and Behavior, 32(6), 775-795.

White, R. \& Stoecklin, V. (1998). Children's Outdoor Play \& Learning Environments: Returning to Nature. Available: www.whitehutchinson.com/children/articles/outdoor.shtml [2001, June 11]. 